\title{
Supplementing an immunomodulatory feed ingredient to modulate thermoregulation, physiologic, and production responses in lactating dairy cows under heat stress conditions
}

\author{
T. Leiva, ${ }^{*}$ R. F. Cooke,$\dagger^{1}$ A. P. Brandão, ${ }^{*} \dagger$ K. M. Schubach, $\dagger$ L. F. D. Batista, ${ }^{*}$ M. F. Miranda, ${ }^{*}$ E. A. Colombo, ${ }^{*}$ \\ R. O. Rodrigues, ${ }^{*}$ J. R. G. Junior, ${ }^{*}$ R. L. A. Cerri,ł and J. L. M. Vasconcelos*1 \\ *Department of Animal Production, São Paulo State University, Botucatu 18168-000, Brazil \\ †Oregon State University, Eastern Oregon Agricultural Research Center, Burns 97720 \\ ¥Faculty of Land and Food Systems, University of British Columbia, Vancouver, BC V6T 1Z4, Canada
}

\begin{abstract}
This study compared vaginal temperature, physiologic, and productive parameters in lactating dairy cows supplemented or not with Omnigen-AF (Phibro Animal Health, Teaneck, NJ) during the summer months in a tropical environment. Thirty-two lactating, primiparous $(\mathrm{n}=16)$ and multiparous $(\mathrm{n}=16)$ pregnant Holstein $\times$ Gir cows were ranked by parity, days in milk, body weight, and body condition score (BCS), and assigned to receive (SUPP; $\mathrm{n}=16)$ or not $(\mathrm{CON} ; \mathrm{n}=16)$ Omnigen-AF (Phibro Animal Health, Teaneck, NJ) at $56 \mathrm{~g} / \mathrm{cow}$ daily (as-fed basis). During the experimental period ( $\mathrm{d}-6$ to 56 ), cows were maintained in a single drylot pen with ad libitum access to water and a total mixed ration, and milked twice daily. Cows received Omnigen-AF mixed with $200 \mathrm{~g}$ of corn (as-fed basis) after the daily morning milking through self-locking head gates, whereas CON cows concurrently received $56 \mathrm{~g}$ of kaolin mixed with $200 \mathrm{~g}$ of corn. For feed intake evaluation, cows from both treatments were randomly divided in 4 groups of 8 cows each, and allocated to 8 individual feeding stations for $3 \mathrm{~d}$. Intake was evaluated 4 times per group from d 1 to 56 . From d -6 to 0 , d 15 to 28 , and d 43 to 56 , cow vaginal temperature was recorded hourly. Environmental temperature-humidity index (THI) was also recorded hourly from d 15 to 28 and d 43 to 56 . Cows were evaluated for body weight and BCS on $\mathrm{d}-6$ and 56 , individual milk production was recorded daily from d -6 to 56 , and milk samples were collected on $\mathrm{d}-6,0,7,14,21,28,35,42,49$, and 56 for analyses of somatic cell count and milk components. Blood samples were collected on d $-6,-3,0,9$, $15,18,21,24,27,36,45,48,51,54$, and 56. Results
\end{abstract}

Received November 4, 2016

Accepted February 13, 2017.

${ }^{1}$ Corresponding authors: vasconcelos@fmvz.unesp.br and reinaldo. cooke@oregonstate.edu from samples or observations collected from $\mathrm{d}-6$ to 0 were included as an independent covariate in each respective analysis. Environmental THI was $74.2 \pm 0.5$ and cows were exposed to THI $>68$ for $633 \mathrm{~h}$ within a total of $672 \mathrm{~h}$ of evaluation. Cows assigned to CON had greater vaginal temperature on d $28,43,45$, and from d 48 to 55 (by 0.38 to $0.52 \%$ ), as well as greater mean somatic cell count (by 97\%) and serum haptoglobin concentrations (by 89\%) compared with SUPP cows. Cows assigned to SUPP had greater mean dry matter intake (by $7 \%$ ), BCS on d 56 (by 11\%), and mean serum insulin concentrations (by $35 \%$ ) compared with CON cows. Hence, SUPP ameliorated hyperthermia, improved nutritional status, and modulated systemic and mammary gland immune parameters in lactating dairy cows exposed to heat stress conditions.

Key words: heat stress, lactating cow, milk production, Omnigen-AF, temperature

\section{INTRODUCTION}

Heat stress is one of the major challenges to dairy production systems in subtropical and tropical environments (West, 2003). St-Pierre et al. (2003) estimated that heat stress costs the US dairy industry approximately $\$ 900$ million annually, whereas decreased milk yield is a critical contributor to this outcome. Hyperthermia is known to affect milk production by reducing voluntary DMI (West, 1994), but also impairs metabolic and physiological processes required for optimal cattle productivity and welfare (West, 2003; Collier et al., 2008; Rhoads et al., 2009). Hence, management strategies that alleviate the incidence of heat stress in dairy cows are warranted to optimize profitability in dairy production systems (West, 2003).

Omnigen-AF is a patented proprietary branded product recently shown to improve milk production and innate immunity parameters in transition dairy cows (Brandão et al., 2016). However, supplementing this 
ingredient has also been associated with decreased hyperthermia in cattle subjected to heat stress conditions. Brandão et al. (2016) reported that supplemented cows had reduced mean vaginal temperature compared with nonsupplemented cohorts during periods with temperature-humidity index (THI; Zimbleman et al., 2009) $>68$. Supplementing this ingredient also decreased rectal temperature and respiration rates in lactating (Hall et al., 2014) and nonlactating (Fabris et al., 2016) dairy cows exposed to elevated thermal and humidity load. Collectively, these results imply that this ingredient affects thermoregulation of dairy cows under heat stress conditions. Yet, research is still warranted to verify its potential thermoregulatory capabilities (Brandão et al., 2016), including supplementation to lactating dairy cows in a production system with elevated incidence of THI $>68$. Therefore, this experiment evaluated the effects of Omnigen-AF supplementation on vaginal temperature, metabolic, physiologic, and productive parameters of lactating dairy cows during the summer months in a tropical environment.

\section{MATERIALS AND METHODS}

This experiment was conducted from December 2015 to February 2016 at the São Paulo State University Lageado Experimental Station located in Botucatu, São Paulo, Brazil. The animals were cared for in accordance with acceptable practices and experimental protocols reviewed and approved by the São Paulo State University Animal Ethics Committee.

\section{Animals and Diets}

Thirty-two lactating, primiparous $(\mathrm{n}=16)$ and multiparous $(\mathrm{n}=16)$ pregnant Holstein $\times$ Gir cows (initial mean $\pm \mathrm{SE} ; \mathrm{BW}=517 \pm 11 \mathrm{~kg}, \mathrm{BCS}=3.06 \pm 0.06$, $\mathrm{DIM}=167 \pm 9,1.6 \pm 0.2$ parities) were assigned to this experiment. On d -6 , cows were ranked by parity, DIM, BW, and BCS (Wildman et al., 1982) in a decreasing order, and alternatingly assigned to receive (SUPP; $\mathrm{n}=16,8$ primiparous and 8 multiparous cows) or not (CON; $\mathrm{n}=16,8$ primiparous and 8 multiparous cows) $56 \mathrm{~g} /$ cow daily (as-fed basis) of Omnigen-AF (Phibro Animal Health, Teaneck, NJ) from d 1 to 56.

During the experimental period ( $\mathrm{d}-6$ to 56 ), cows were maintained in a single drylot pen with ad libitum access to water and a TMR (1.5 m of linear bunk space/cow). The drylot pen had no available shade or cooling system. The TMR consisted (DM basis) of $58.9 \%$ corn silage and $41.1 \%$ concentrate (Table 1) and was formulated with the Spartan Dairy Ration Evaluator/Balancer (version 3.0; Michigan State University,
East Lansing, MI) to yield $25 \mathrm{~kg}$ of milk/d. Cows were milked twice daily in a side-by-side milking system (0600 and $1700 \mathrm{~h}$ ) from d -6 to 56 .

From d 1 to 56, SUPP cows individually received 56 $\mathrm{g}$ of Omnigen-AF mixed with $200 \mathrm{~g}$ of finely ground corn (as-fed basis), immediately after the daily morning milking $(0800 \mathrm{~h})$ through self-locking head gates. The feed bunk containing the self-locking head gates had no shade, but contained a sprinkler + fan cooling system. Each CON cow concurrently received $56 \mathrm{~g}$ of kaolin (rumen-inert substance) mixed with $200 \mathrm{~g}$ of finely ground corn (as-fed basis) through self-locking head gates. Omnigen-AF was offered in the amount recommended by the manufacturer (Phibro Animal Health) and used in previous research (Wang et al., 2009; Ryman et al., 2013; Brandão et al., 2016).

\section{Sampling}

Intake Parameters. Samples of the offered TMR were collected weekly, pooled into one sample, and analyzed for nutrient content (Table 1) via wet chemistry procedures by a bromatology laboratory (3rlab, Belo Horizonte, Brazil). Calculations of $\mathrm{ME}, \mathrm{NE}_{\mathrm{l}}$, and $\mathrm{NE}_{\mathrm{m}}$ used the equation proposed by the NRC (2001).

To determine treatment effects on voluntary DMI from d 1 to 56 , cows from both treatments were randomly divided in 4 groups of 8 cows each (4 cows/treatment in each group, being 2 primiparous and 2 multiparous from each treatment). Cows from each group were allocated to 8 individual feeding stations $\left(15 \mathrm{~m}^{2}\right.$; $2.0 \mathrm{~m}$ of linear bunk space) with soft rubber flooring for

Table 1. Composition and nutritional profile of the TMR offered for ad libitum consumption to lactating dairy cows during the experimental period

\begin{tabular}{lc}
\hline Item & Component \\
\hline Composition (DM basis) & \\
Corn silage, \% & 58.87 \\
Soybean meal, \% & 20.57 \\
Ground corn, \% & 18.93 \\
Mineral mix, \% & 1.23 \\
Urea, \% & 0.40 \\
Nutritional profile (DM basis) & \\
NDF, \% & 40.69 \\
Starch, \% & 18.49 \\
ME, Mcal/kg & 2.57 \\
NE, Mcal/kg & 1.62 \\
$\mathrm{NE}_{\mathrm{L}}, \mathrm{Mcal} / \mathrm{kg}$ & 1.62 \\
$\mathrm{NE}_{\mathrm{G}}, \mathrm{Mcal} / \mathrm{kg}$ & 1.08 \\
$\mathrm{CP}, \%$ & 15.60 \\
\hline
\end{tabular}

${ }^{1}$ Contained $22 \% \mathrm{Ca}, 7.5 \% \mathrm{P}, 6.5 \% \mathrm{Na}, 1.0 \% \mathrm{~K}, 3.6 \% \mathrm{Mg}, 2.0 \% \mathrm{~S}$, $0.003 \% \mathrm{Co}, 0.115 \% \mathrm{Cu}, 0.004 \% \mathrm{I}, 0.220 \% \mathrm{Mn}, 0.003 \% \mathrm{Se}, 0.400 \% \mathrm{Zn}$, $400,000 \mathrm{IU} / \mathrm{kg}$ of vitamin $\mathrm{A}, 100,000 \mathrm{IU} / \mathrm{kg}$ of vitamin $\mathrm{D}_{3}$, and $0.150 \%$ of vitamin E (Milk MAC, M. Cassab Tecnologia Animal, São Paulo, Brazil). 
3 d. During this period, cows from the selected group continued to have ad libitum access to water and a TMR, and received treatments after milking as previously described. The TMR intake was evaluated daily from each feeding station by collecting and weighing refusals daily. Samples of the offered and nonconsumed TMR were collected daily from each feeding station and dried for $96 \mathrm{~h}$ at $50^{\circ} \mathrm{C}$ in forced-air ovens for DM calculation. At the end of the 3 -d period, cows returned to the drylot pen and another group was assigned to the individual feeding stations, in a manner that DMI was evaluated 4 times/group during the experimental period.

Temperature Parameters. From d -6 to 0 , d 15 to 28 , and d 43 to 56 , cows were fitted intravaginally with a thermometer (iButton temperature loggers DS1922L, Maxim Integrated, San Jose, CA) attached to a controlled internal drug-releasing device (CIDR, Zoetis, São Paulo, SP, Brazil) that did not contain hormones. Cow vaginal temperature was recorded hourly during the $6-\mathrm{d}$ (d -6 to $0 ; \mathbf{P R 1})$ or each 14-d period (d 15 to 28, PR2; d 43 to 56, PR3). Length ( $\leq 14$ d) and interval (15 d) among PR1, PR2, and PR3 were planned to prevent vaginal or uterine disorders caused by thermometer insert, which could interfere with the objectives of this experiment.

Environmental temperature, relative humidity, and THI (Willard et al., 2003) were recorded hourly using 2 HOBO Water Temp Pro V2 data loggers (Onset Company, Bourne, MA) from d 15 to 28 and d 43 to 56 . Each device was kept in the shade, with 1 device located adjacent to the drylot pen and the other device located in the individual feeding station facility. Data from both devices were averaged for overall environmental conditions during the experiment. Data were summarized (mean $\pm \mathrm{SE}$ ) as daily THI, and hourly THI across days (Figures $1 \mathrm{a}$ and $1 \mathrm{~b}$ ). During PR1, PR2, and PR3, cows were also evaluated for total hours with temperature $\geq 39.1^{\circ} \mathrm{C}, \%$ of hours with temperature $\geq 39.1^{\circ} \mathrm{C}$, and mean vaginal temperature when THI was $>68$ (Zimbleman et al., 2009) as previously reported by Brandão et al. (2016).

Cow Productive Parameters. Cows were monitored daily during the entire experimental period for incidence of morbidity or mortality by trained personnel (Lima et al., 2012). No incidences of morbidity of mortality were observed. Cows were evaluated for BW and $\mathrm{BCS}$ on $\mathrm{d}-6$ and 56 . Cows were weighed on a platform scale (Precision Balanças, Tupã, SP, Brazil), and BCS was assessed according to Wildman et al. (1982) by the same 2 evaluators that were blinded to distribution of cows across treatments.

Individual milk production was recorded daily from $\mathrm{d}-6$ to 56 . The milking parlor had no cooling system, but cows were maintained in the shade before and during milking. Milk samples were collected on d $-6,0$, $7,14,21,28,35,42,49$, and 56 from each cow during both milkings of the day, which were combined into 1 daily sample (50 $\mathrm{mL}$ from each milking). Milk samples were analyzed for SCC via flow cytometry (AOAC, 1990) with a Somacount 300 instrument (Bentley Instruments Inc., Chaska, MN), and concentrations of fat, lactose, protein, and TS via infrared spectrometry (method 972.16; AOAC International, 1999), by a commercial laboratory (Clínica do Leite; Universidade de São Paulo, Piracicaba, Brazil). Daily milk yield was adjusted to FCM or TS-corrected milk based on milk concentrations of fat and TS, respectively, of the concurrent week.

Physiological and Metabolic Parameters. Blood samples were collected on d $-6,-3,0,9,15,18,21$, $24,27,36,45,48,51,54$, and 56, immediately before morning treatment administration $(0600 \mathrm{~h})$. All blood samples were obtained from either the coccygeal vein or artery into commercial blood collection tubes (Vacutainer, $10 \mathrm{~mL}$; Becton Dickinson, Franklin Lakes, NJ), placed immediately on ice, centrifuged at $1,500 \times g$ at $4^{\circ} \mathrm{C}$ for $30 \mathrm{~min}$ for serum collection, and stored at $-20^{\circ} \mathrm{C}$ on the same day of collection.

All samples were analyzed for serum concentrations of glucose (colorimetric kit \#G7521, Pointe Scientific Inc., Canton, MI), nonesterified fatty acids (NEFA; colorimetric kit HR Series NEFA-2, Wako Pure Chemical Industries Ltd. USA, Richmond, VA), haptoglobin (colorimetric assay; Cooke and Arthington, 2013), IGFI, cortisol, and insulin (chemiluminescent enzyme immunoassay, Immulite 1000; Siemens Medical Solutions Diagnostics, Los Angeles, CA). Insulin-to-glucose ratio (I:G) was determined by dividing insulin and glucose concentrations within each sampling time (Bernhard et al., 2012). The intra- and interassay CV were, respectively, 3.1 and $4.3 \%$ for glucose, 4.3 and $3.5 \%$ for NEFA, and 2.0 and $4.8 \%$ for haptoglobin. Serum IGF-I, cortisol, and insulin concentration were analyzed within single assays, and the intra-assay CV were, respectively, $3.1,1.4$, and $0.4 \%$.

\section{Statistical Analysis}

Sample size was defined based on the capacity of the research facility, which was adequate to test similar research hypotheses in previous studies from our group (Leiva et al., 2015, 2016; Brandão et al., 2016). Thermometers (iButton temperature loggers DS1922L) used herein were incubated for $48 \mathrm{~h}$ at $38^{\circ} \mathrm{C}$ (Symphony Incubating Orbital Shaker Model 5000I, Troemner, LLC, Thorofare, NJ), and temperature was recorded hourly. During the experiment, cows were always inserted with 
the same thermometer. Hence, average temperature during the 48-h incubation period for each thermometer was included as a covariate in the vaginal temperature statistical analysis. Average \pm SEM temperature during incubation among all thermometers was $37.92 \pm$ $0.07^{\circ} \mathrm{C}$.

Quantitative and binary data were analyzed, respectively, with the MIXED and GLIMMIX procedures of SAS (version 9.3, SAS Institute Inc., Cary, NC) using cow as the experimental unit. The model statement used for analysis of BW and BCS change, as well as ini- tial and final BCS and BW during the experiment contained the effects of treatment, party, and the resultant interaction, with cow(treatment $\times$ parity) as a random variable. The model statement used for analysis of milk yield, milk constituents, and serum variables contained the effects of treatment, day, parity, and all resultant interactions. Cow(treatment $\times$ parity) was used as a random variable, whereas the specified term for the repeated statements was day with cow(treatment $\times$ parity) as subject. The model statement used for analysis of DMI contained the effects of treatment, day,

(A)

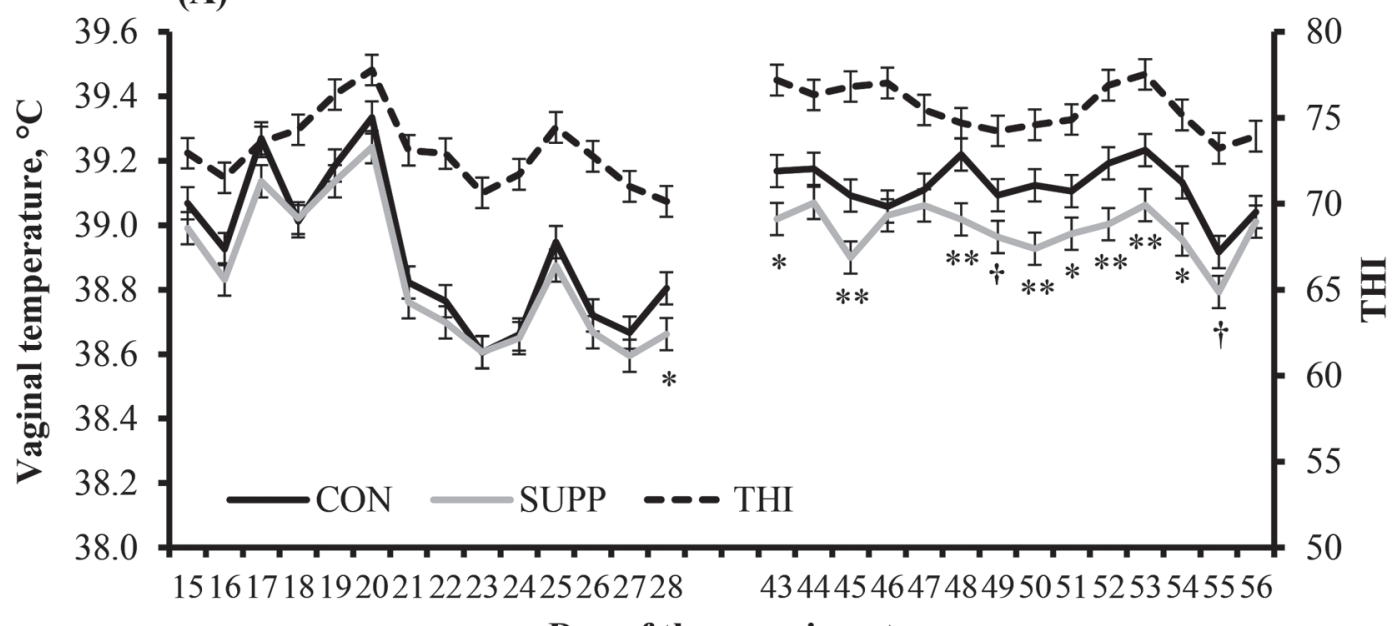

Day of the experiment

(B)

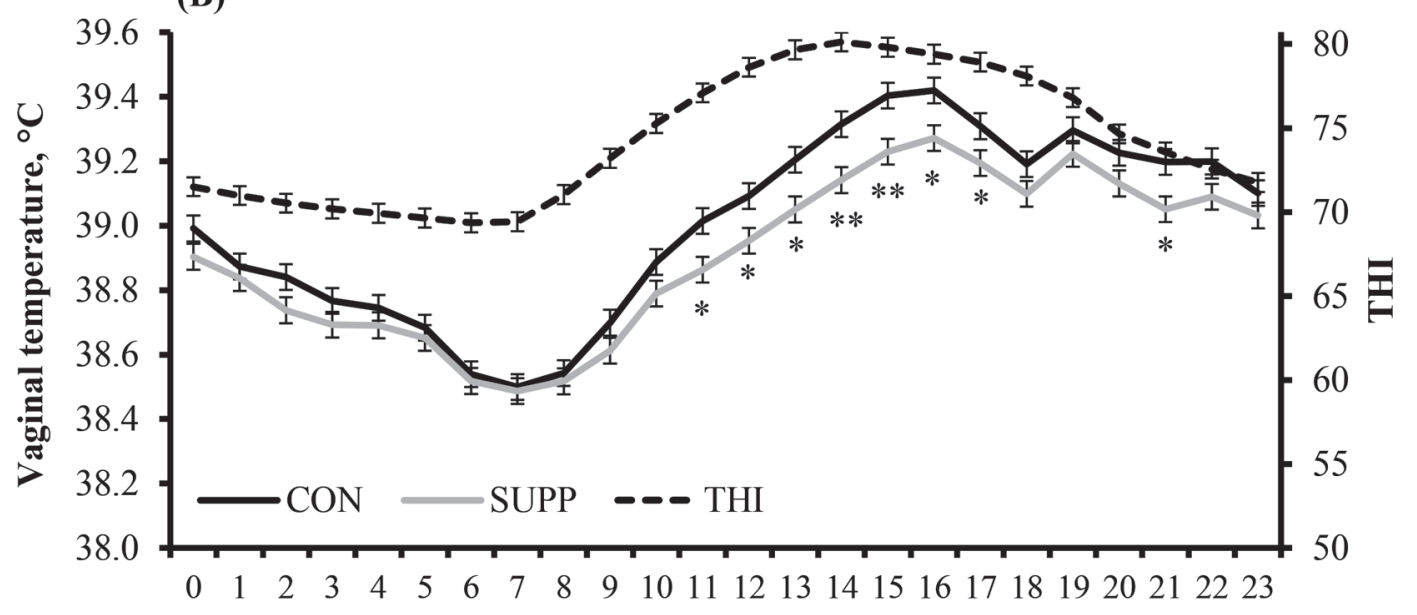

Hour of the day

Figure 1. Environmental temperature-humidity index (THI; Willard et al., 2003) and vaginal temperature in dairy cows supplemented with an immunomodulatory feed ingredient (SUPP; Omnigen-AF, Phibro Animal Health, Teaneck, NJ; $\mathrm{n}=16)$ or not (CON; $\mathrm{n}=16$ ) from d 1 to 56 of the experiment. Values were recorded hourly (d -6 to 0 , d 15 to 28, and d 43 to 56 of the experiment) using intravaginal thermometers (iButton temperature loggers DS1922L, Maxim Integrated, San Jose, CA) or HOBO Water Temp Pro V2 data loggers for THI (Onset Company, Bourne, MA). Treatment $\times$ day (panel A) and treatment $\times$ hour (panel B) interactions were detected $(P \leq 0.01)$, which included averaged results from d -6 to 0 as an independent covariate. Hence, values reported are covariately adjusted means. Error bars represent SEM. Within day or hour, ${ }^{* *} P \leq 0.01,{ }^{*} P \leq 0.05, \dagger P \leq 0.09$. 
group, parity, and all resultant interactions. Cow(group $\times$ treatment $\times$ parity) was used as random variable, whereas the specified term for the repeated statements was day (group) with cow(group $\times$ treatment $\times$ parity) as subject. The model statement used for analysis of vaginal temperature contained the effects of treatment, period (PR2 or PR3), day, hour, parity, and all resultant interactions. Cow (group $\times$ period $\times$ parity) was used as a random variable, whereas the specified term for the repeated statements was hour(day $\times$ period) with cow $($ group $\times$ period $\times$ parity $\times$ day) as subject. The model statement for vaginal temperature variables when THI was $>68$ was analyzed using treatment, parity, period (PR2 or PR3), and all resultant interactions, with cow(treatment $\times$ parity) as a random variable. All vaginal temperature analyses contained thermometer incubation temperature, in addition to averaged results from samples or observations collected from PR1 as independent covariates. The covariance structure used for all repeated statements was autoregressive, which provided the best fit for these analyses according to the Akaike information criterion. Significance was set at $P$ $\leq 0.05$, and tendencies were determined if $P>0.05$ and $\leq 0.10$. Results are reported as least squares means, or covariately adjusted means for analyses that included a covariate, and separated using least square differences. Results are reported according to treatment effects if no interactions were significant, or according to the highest-order interaction detected that contained the effects of treatment.

\section{RESULTS}

\section{Temperature Parameters}

While environmental THI was being recorded, mean $( \pm \mathrm{SE}) \mathrm{THI}$ was $74.2 \pm 0.5$, and cows were exposed to THI $>68$ for $633 \mathrm{~h}$ within a total of $672 \mathrm{~h}$. Moreover, mean THI during PR2 was less $(P \leq 0.01)$ compared with mean THI of PR3 (73.1 vs. 75.4 , respectively; $\mathrm{SEM}=0.5)$.

A treatment $\times$ day interaction was detected $(P \leq$ 0.01; Figure 1a) for vaginal temperature, given that CON cows had greater (by 0.38 to $0.52 \%$ ) temperatures on d 28, 43, $45(P \leq 0.05)$, and from d 48 to 55 of the experiment $(P \leq 0.09)$ compared with SUPP cows. A treatment $\times$ hour interaction was also detected $(P=$ 0.01 ), as vaginal temperatures were greater in $\mathrm{CON}$ versus SUPP cows (by 0.29 to $0.44 \%$ ) from 1100 to $1700 \mathrm{~h}(P \leq 0.04)$, and at $2100 \mathrm{~h}(P \leq 0.01$; Figure $1 \mathrm{~b})$.

Treatment $\times$ period interactions were detected $(P$ $\leq 0.04$ ) for vaginal temperature parameters when THI was $>68$ (Table 2). More specifically, no treatment differences were detected $(P \geq 0.21)$ for these parameters during PR2. However, CON cows had more $(P=0.02)$ time with vaginal temperature $\geq 39.1$ (by $30 \%$ ), greater $(P=0.03)$ percentage of time with vaginal temperature $\geq 39.1$ (by $27 \%$ ), and tended $(P=0.10)$ to have greater mean vaginal temperature (by $0.28 \%$ ) compared with SUPP cohorts when THI was $>68$ during PR3 (Table $2)$.

Table 2. Vaginal temperature parameters of dairy cows supplemented with an immunomodulatory feed ingredient (SUPP; $\mathrm{n}=16)$ or not $(\mathrm{CON} ; \mathrm{n}=16)$ during heat stress conditions [temperature-humidity index (THI) >68; Zimbleman et al., 2009] $]^{1,2}$

\begin{tabular}{|c|c|c|c|c|}
\hline Item $^{3}$ & SUPP & $\mathrm{CON}$ & SEM & $P$-value \\
\hline \multicolumn{5}{|c|}{ Time with temperature $\geq 39.1^{\circ} \mathrm{C}, \mathrm{h}$} \\
\hline $\mathrm{PR} 2$ & 91.3 & 112.3 & 11.4 & 0.21 \\
\hline PR3 & 128.3 & 167.5 & 11.4 & 0.02 \\
\hline \multicolumn{5}{|c|}{ Hours with temperature $\geq 39.1^{\circ} \mathrm{C}, \%$} \\
\hline PR2 & 30.5 & 37.4 & 3.7 & 0.21 \\
\hline PR3 & 43.2 & 54.8 & 3.7 & 0.03 \\
\hline \multicolumn{5}{|c|}{ Mean temperature, ${ }^{\circ} \mathrm{C}$} \\
\hline PR2 & 38.88 & 38.91 & 0.05 & 0.62 \\
\hline PR3 & 39.01 & 39.12 & 0.05 & 0.10 \\
\hline
\end{tabular}

${ }^{1}$ From d 1 to 56 of the experiment, $56 \mathrm{~g}$ of Omnigen-AF (Phibro Animal Health, Teaneck, NJ) was mixed with $200 \mathrm{~g}$ of finely ground corn (as-fed basis) and offered individually to each SUPP cow at $0800 \mathrm{~h}$. Each CON cow concurrently received $56 \mathrm{~g}$ of kaolin mixed with $200 \mathrm{~g}$ of finely ground corn (as-fed basis).

${ }^{2}$ From d -6 to 0 (PR1, used as covariate), d 15 to 28 (PR2), and d 43 to 56 (PR3), cows were fitted intravaginally with a thermometer (iButton temperature loggers DS1922L, Maxim Integrated, San Jose, CA) attached to a controlled internal drug-releasing device (CIDR, Zoetis, São Paulo, SP, Brazil) that did not contain hormones. Cow vaginal temperature was recorded hourly. Environmental THI (Willard et al., 2003) was also recorded hourly using HOBO Water Temp Pro V2 data loggers (Onset Company, Bourne, MA) during PR2 and PR3.

${ }^{3}$ Treatment $\times$ period interactions were detected $(P \leq 0.04)$ for all variables, which were analyzed using averaged results from PR1 as an independent covariate. Hence, values reported are covariately adjusted means. 
Table 3. Body weight and BCS of dairy cows supplemented with an immunomodulatory feed ingredient $(\mathrm{SUPP} ; \mathrm{n}=16)$ or $\operatorname{not}(\mathrm{CON} ; \mathrm{n}=16)^{1}$

\begin{tabular}{lcccc}
\hline Item & SUPP & CON & SEM & $P$-value \\
\hline DMI, ${ }^{2} \mathrm{~kg} / \mathrm{d}$ & 18.0 & 16.8 & 0.5 & 0.10 \\
BW, kg & 512 & 522 & 15 & 0.65 \\
Initial BW (d -6) & 519 & 518 & 14 & 0.97 \\
Final BW (d 56) & 7.2 & -3.4 & 4.5 & 0.10 \\
BW change (d -6 to 56) & & & & \\
BCS & 3.10 & 3.01 & 0.08 & 0.42 \\
Initial BCS (d -6) & 3.34 & 3.01 & 0.12 & 0.05 \\
Final BCS (d 56) & 0.23 & 0.00 & 0.07 & 0.03 \\
BCS change (d -6 to 56) &
\end{tabular}

${ }^{1}$ From d 1 to 56 of the experiment, $56 \mathrm{~g}$ of Omnigen-AF (Phibro Animal Health, Teaneck, NJ) was mixed with $200 \mathrm{~g}$ of finely ground corn (as-fed basis) and offered individually to each SUPP cow at $0800 \mathrm{~h}$. Each CON cow concurrently received $56 \mathrm{~g}$ of kaolin mixed with $200 \mathrm{~g}$ of finely ground corn (as-fed basis).

${ }^{2}$ Cows from both treatments were randomly divided in 4 groups of 8 cows each, and allocated to 8 individual feeding stations $\left(15 \mathrm{~m}^{2} ; 2.0 \mathrm{~m}\right.$ of linear bunk space) for $3 \mathrm{~d}$. The TMR intake was evaluated daily from each feeding station by collecting and weighing refusals daily. At the end of the 3-d period, cows returned to the drylot pen and another group was assigned to the individual feeding stations, in a manner that DMI was evaluated 4 times/group during the experimental period.

${ }^{3}$ According to Wildman et al. (1982) and assessed by 2 evaluators that were blinded to distribution of cows across treatments.

\section{Intake and Cow Productive Parameters}

During the experimental period, there was a statistical tendency $(P=0.10)$ for SUPP cows to have greater DMI (by 7\%) and BW change (Table 3) compared with CON cows (Table 3$)$. Cow BCS change was also greater $(P=0.03)$ in SUPP versus CON cows (Table 3$)$. Final BCS was greater $(P=0.05$; by $11 \%)$ in SUPP versus CON cows, although final BW did not differ $(P=0.97)$ among treatments (Table 3).
No treatment differences were detected for $(P \geq 0.26)$ milk production parameters (Table 4 ), as well as milk concentrations of protein, fat, lactose, and TS (Table 4). Somatic cell count was greater $(P=0.01$; by $97 \%)$ in CON versus SUPP cows (Table 4).

\section{Physiologic and Metabolic Parameters}

During the experimental period, a statistical tendency $(P=0.09)$ was observed for SUPP cows to have greater

Table 4. Milk production parameters of dairy cows supplemented with an immunomodulatory feed ingredient $(\mathrm{SUPP} ; \mathrm{n}=16)$ or $\operatorname{not}(\mathrm{CON} ; \mathrm{n}=16)^{1,2}$

\begin{tabular}{|c|c|c|c|c|}
\hline Item $^{3}$ & SUPP & $\mathrm{CON}$ & SEM & $P$-value \\
\hline \multicolumn{5}{|l|}{ Milk production } \\
\hline Milk yield, kg/d & 21.0 & 20.3 & 0.4 & 0.26 \\
\hline $3.5 \% \mathrm{FCM}, \mathrm{kg} / \mathrm{d}$ & 28.9 & 29.2 & 0.97 & 0.82 \\
\hline $12 \%$ TS-corrected milk, $\mathrm{kg} / \mathrm{d}$ & 22.4 & 22.4 & 0.7 & 0.97 \\
\hline \multicolumn{5}{|l|}{ Milk component } \\
\hline Milk fat, $\%$ & 4.79 & 5.05 & 0.13 & 0.17 \\
\hline Milk protein, \% & 3.10 & 3.15 & 0.03 & 0.30 \\
\hline Milk lactose, \% & 4.54 & 4.53 & 0.02 & 0.85 \\
\hline Milk TS, \% & 13.43 & 13.72 & 0.14 & 0.17 \\
\hline $\mathrm{SCC}$, cells $/ \mu \mathrm{L}$ & 384 & 759 & 103 & 0.01 \\
\hline
\end{tabular}

${ }^{1}$ From d 1 to 56 of the experiment, $56 \mathrm{~g}$ of Omnigen-AF (Phibro Animal Health, Teaneck, NJ) was mixed with $200 \mathrm{~g}$ of finely ground corn (as-fed basis) and offered individually to each SUPP cow at $0800 \mathrm{~h}$. Each CON cow concurrently received $56 \mathrm{~g}$ of kaolin mixed with $200 \mathrm{~g}$ of finely ground corn (as-fed basis).

${ }^{2}$ Individual milk production was recorded daily from $\mathrm{d}-6$ to 56 . Milk samples were collected on d $-6,0,7$, $14,21,28,35,42,49$, and 56 from each cow during both milkings of the day, which were combined into 1 daily sample (50 mL from each milking). Milk samples were analyzed for SCC via flow cytometry (AOAC, 1990) with a Somacount 300 instrument (Bentley Instruments Inc., Chaska, MN), and concentrations of fat, lactose, protein, and TS were analyzed via infrared spectrometry (method 972.16; AOAC, 1999) by a commercial laboratory (Clínica do Leite, Universidade de São Paulo, Piracicaba, Brazil). Daily milk yield was adjusted to FCM or TS-corrected milk based on milk concentrations of fat and TS, respectively, of the concurrent week. ${ }^{3}$ Results from $\mathrm{d}-6$ to 0 were averaged when appropriate and used as an independent covariate. Hence, values reported are covariately adjusted means. 
Table 5. Serum parameters of dairy cows supplemented with an immunomodulatory feed ingredient (SUPP; $\mathrm{n}=16)$ or $\operatorname{not}(\mathrm{CON} ; \mathrm{n}=16)^{1}$

\begin{tabular}{lcccc}
\hline Item $^{2}$ & SUPP & CON & SEM & $P$-value \\
\hline Cortisol, $\mathrm{ng} / \mathrm{mL}$ & 8.32 & 8.31 & 0.61 & 0.99 \\
Glucose $\mathrm{mg} / \mathrm{dL}$ & 63.0 & 64.2 & 0.8 & 0.30 \\
Haptoglobin, $\mu \mathrm{g} / \mathrm{mL}$ & 123 & 233 & 39 & 0.05 \\
IGF-I, $\mathrm{ng} / \mathrm{mL}$ & 161 & 166 & 19 & 0.87 \\
Insulin, $\mathrm{pmol} / \mathrm{L}$ & 3.73 & 2.75 & 0.43 & 0.09 \\
NEFA, $\mu \mathrm{Eq} / \mathrm{L}$ & 0.245 & 0.259 & 0.011 & 0.38 \\
Insulin:glucose ratio & 0.059 & 0.043 & 0.007 & 0.16 \\
\hline
\end{tabular}

${ }^{1}$ From d 1 to 56 of the experiment, $56 \mathrm{~g}$ of Omnigen-AF (Phibro Animal Health, Teaneck, NJ) was mixed with $200 \mathrm{~g}$ of finely ground corn (as-fed basis) and offered individually to each SUPP cow at $0800 \mathrm{~h}$. Each CON cow concurrently received $56 \mathrm{~g}$ of kaolin mixed with $200 \mathrm{~g}$ of finely ground corn (as-fed basis).

${ }^{2}$ Blood samples were collected on d $-6,-3,0,9,15,18,21,24,27,36,45,48,51,54$, and 56 of the experiment before treatment administration. Results from d -6 to 0 were averaged and used as an independent covariate. Hence, values reported are covariately adjusted means. NEFA $=$ nonesterified fatty acids.

mean serum insulin concentrations (by 35\%) compared with CON cows (Table 5). Mean serum haptoglobin concentration was greater $(P=0.05$; by $89 \%)$ in $\mathrm{CON}$ versus SUPP cows (Table 5). No treatment differences were detected $(P \geq 0.16)$ for serum concentrations of cortisol, glucose, IGF-I, NEFA, and I:G (Table 5).

\section{DISCUSSION}

According to the THI values observed herein (Figure $1 \mathrm{a}, \mathrm{b})$, cows were exposed to heat stress conditions during the vast majority of the experimental period (Zimbleman et al., 2009), as expected based on the location and time of the year in which this research was conducted. Supporting our hypothesis and previous research (Brandão et al., 2016), SUPP reduced vaginal temperatures in lactating dairy cows exposed to heat stress conditions (Figure 1a; Table 2). Treatment differences for vaginal temperature were more evident during PR3 (d 43 to 56) of temperature evaluation (Figure 1a), which is corroborated by the treatment $\times$ period interaction detected for vaginal temperature parameters recorded when THI $>68$ (Table 2). This outcome can be attributed to the greater THI observed during PR3 versus PR2 (Figure 1a), suggesting that the THI threshold in which SUPP ameliorated hyperthermia in dairy cows may be greater than the THI value associated with heat stress (68; Zimbleman et al., 2009). Nevertheless, no treatment differences were detected for vaginal temperatures during days within PR2 (i.e., d 18 to 21) when THI was equivalent to levels observed during PR3. This may also suggest that a delay is present between SUPP feeding and its thermoregulatory effects, although research is warranted to validate both assumptions.

Similar to our findings, Hall et al. (2014) reported that supplementation with Omnigen-AF reduced rectal temperatures in lactating cows exposed to heat stress conditions (THI $>68$ for $16 \mathrm{~h} / \mathrm{d}$ ) within environmentally controlled rooms. Yet, the same result was not observed when cows were exposed to a thermoneutral environment (THI $\leq 68$ ). Similar outcomes were reported by Fabris et al. (2016) evaluating nonlactating dairy cows exposed or not to heat stress conditions, and supplemented or not with this ingredient. Collectively, these results suggest that this feed ingredient reduced hyperthermia in cows during heat stress episodes, but not when cows were exposed to thermoneutral environments. Accordingly, the treatment $x$ hour interaction detected herein for vaginal temperature (Figure 1b) demonstrates that SUPP ameliorated the hyperthermia caused by the circadian increase in THI, but not when THI were at the lowest levels. Figure $1 \mathrm{~b}$ also suggests the presence of a 1-h lag between circadian increase or decrease in THI with respective changes in vaginal temperature, which may help explaining why vaginal temperatures differed between CON and SUPP cows when THI was $\geq 75$. Nevertheless, the exact mechanisms by which this feed ingredient modulates thermoregulation in cows exposed to heat stress conditions remains unclear and requires further investigation. It is also important to note that mean vaginal temperature in CON during each day and throughout the experimental period were, respectively, $0.09 \pm 0.01^{\circ} \mathrm{C}$ and $0.11 \pm 0.01^{\circ} \mathrm{C}$ greater than SUPP cows, with a maximal difference of $0.20^{\circ} \mathrm{C}$. Therefore, the biological significance of this outcome may be questionable, particularly regarding its effects on cattle welfare and productive parameters.

Treatment differences detected for DMI (Table 3 ), however, denote the productive implications of decreased vaginal temperature in SUPP versus CON cows, and corroborate the rationale that hyperthermia directly affects voluntary feed intake (West, 1994; Rhoads et al., 2009). Hence, SUPP reduced body temperature and allowed cows to consume more DM during heat stress conditions herein, as also reported by Hall 
et al. (2014). Moreover, DMI is positively associated with metabolic heat increment (Kadzere et al., 2002), whereas the opposing treatment differences in vaginal temperature and DMI suggests enhanced thermoregulatory ability of SUPP cows during heat stress conditions. However, DMI differences among treatments were not sufficient to affect milk yield parameters (Table 4). Hall et al. (2014) also failed to detected effects of this ingredient on milk yield in heat-stressed dairy cows. One could speculate that cows in this experiment were already producing their maximum milk yield (Leiva et al., 2015, 2016) and the additional nutrients consumed by SUPP cows were converted into BCS, which would explain treatment differences detected for this latter variable (Table 3). Treatment differences detected for serum insulin (Table 5) further support this rationale, given that circulating insulin concentrations are positively modulated by nutrient intake in cattle (Vizcarra et al., 1998; Butler, 2003). Accordingly, Rhoads et al. (2009) suggested that DMI only accounts for 35\% of the milk yield decrease in dairy cattle exposed to heat stress conditions, whereas other mechanisms such as NEFA metabolism and the somatotropic axis modulate this outcome. Hence, similar serum concentrations of glucose, NEFA, and IGF-I between SUPP and CON cows reported herein (Table 5) corroborate the similar milk yield among treatments, as well as the rationale proposed by Rhoads et al. (2009).

Circulating glucose, NEFA, and IGF-I concentrations, however, are also modulated by nutrient intake (Vazquez-Añon et al., 1994; Jorritsma et al., 2003). Thus, it could be expected that SUPP cows also had altered serum concentrations of these variables due to their increased DMI compared with CON cows. Increased circulating insulin concentrations without similar changes in circulating glucose and NEFA can be associated with reduced insulin sensitivity in cows gaining BCS (Leiva et al., 2015, 2016). Yet, I:G was similar between SUPP and CON cows, which is used to estimate insulin sensitivity in dairy cattle (Bernhard et al., 2012). Consequently, it can be concluded that increased DMI of SUPP cows were not sufficient to affect serum concentrations of glucose, NEFA, and IGFI, but resulted in greater serum insulin concentrations and BCS change compared with CON cohorts as cows from both treatments were likely at their maximum milk yield potential (Leiva et al., 2015, 2016).

During heat stress, cows experience a heightened adrenocortical function, culminating in increased circulating concentrations of cortisol (Beede and Collier, 1986; Wise et al., 1988; De Rensis and Scaramuzzi, 2003). In the present experiment, however, serum cortisol concentrations were similar between SUPP and CON cows despite treatment differences in vaginal temperature. It can be speculated that treatment differences in vaginal temperature were not sufficient to affect adrenocortical function. Nevertheless, circulating cortisol concentrations are transiently affected by stress stimuli (Christison and Johnson, 1972). In the present experiment, blood samples were collected at $0600 \mathrm{~h}$, when vaginal temperatures were not only similar among SUPP and CON cows, but also at their lowest value during the day along with THI. Hence, the time of blood collection may have prevented proper treatment assessment in serum cortisol concentrations. Accordingly, Hall et al. (2014) reported that cows supplemented with this feed ingredient had less serum cortisol concentrations compared with nonsupplemented cohorts in blood samples collected when cows were initially exposed to heat stress within environmentally controlled chambers, but not before or after $7 \mathrm{~d}$ of heat stress exposure. In addition, handling cows for blood sampling also elicited an acute stress response that rapidly increased circulating cortisol concentrations (Cook et al., 2000). Alternatives that assess long-term circulating cortisol levels, such as cortisol concentrations in hair from the tail switch (Burnett et al., 2014), should be considered for future evaluation of SUPP on adrenocortical parameters during heat stress conditions.

Elevated cortisol concentrations have also been positively associated with circulating haptoglobin concentrations in cattle (Cooke and Bohnert, 2011; Cooke et al., 2012), which is a key component of the bovine acute-phase response (Carroll and Forsberg, 2007). Dairy goats exposed to heat stress conditions had greater plasma haptoglobin concentrations compared with cohorts exposed to thermoneutral conditions (Hamzaoui et al., 2013). On the other hand, supplementation with this ingredient has been shown to increase serum haptoglobin concentration in dairy and beef cattle following a pathogen challenge such as LPS (Burdick et al., 2012; Burdick Sanchez et al., 2014; Brandão et al., 2016), but not in transition dairy cows during routine management (Brandão et al., 2016). Therefore, treatment differences detected herein for serum haptoglobin concentrations provide evidence that CON cows experienced heightened adrenocortical function due to increased hyperthermia, which resulted in greater serum haptoglobin concentrations compared with SUPP cohorts. Furthermore, SUPP effects on serum haptoglobin concentrations reported herein differ from Brandão et al. (2016) due to lack of LPS challenge, and the need for this feed ingredient to yield a stronger acute-phase response to control pathogenic infection and restore homeostasis (Abbas and Lichtman, 2007).

Treatment differences detected herein (Table 4) for milk SCC were also reported by others, corroborating the immunological benefits attributed to this feed 
ingredient (Wang et al., 2009; Ryman et al., 2013; Brandão et al., 2016). Chapman et al. (2016) reported that supplementation to commercial dairy herds decreased milk SCC by up to $30 \%$, although incidence of heat stress was not accounted for by these authors. Hall et al. (2014) reported that milk SCC was similar between supplemented versus nonsupplemented cows before and during a 10-d heat stress period (THI >68 for $16 \mathrm{~h} / \mathrm{d}$ ), but greater for nonsupplemented cows during the $4 \mathrm{~d}$ after the heat stress period. Brandão et al. (2016) did not report differences milk SCC between supplemented versus nonsupplemented cows, although these authors evaluated transition dairy cows and only assessed heat stress conditions after SCC evaluation was completed. These results indicate that supplementing this ingredient reduces milk SCC in dairy cows, particularly when cattle are exposed to heat stress conditions (Giesecke, 1985). In addition, mammary gland infection and inflammation that lead to increased milk SCC also yield an acute-phase reaction, which in turn increase circulating concentrations of haptoglobin (Murata et al., 2004; Nyman et al., 2008). Therefore, treatment differences in SCC also contributed to the greater serum haptoglobin concentrations in $\mathrm{CON}$ versus SUPP cows. Yet, treatment effects reported herein for SCC should be interpreted with caution, given that SCC was evaluated weekly in a limited population of cows during a 56-d period. Additional research is still warranted to investigate the effects of the treatments evaluated herein on mammary gland health of lactating dairy cows.

In conclusion, offering SUPP to lactating dairy cows exposed to heat stress conditions reduced hyperthermia. In turn, SUPP cows had greater DMI but similar milk yield, resulting in greater BCS gain compared with CON cows. Moreover, SUPP cows had less milk SCC and serum haptoglobin concentrations compared with CON, which can be attributed to immunomodulatory effects of this ingredient on systemic and mammary gland innate immune reactions elicited by heat stress. The exact mechanisms by which this ingredient modulates thermoregulation in dairy cows are still unknown and deserve investigation. Additional research is also needed to evaluate the effects of SUPP on thermoregulation and productive responses of dairy cows in different management scenarios. These include high-producing Holstein cows with greater susceptibility to heat stress than cows evaluated herein. Nevertheless, this experiment demonstrated that Omnigen-AF supplementation appears to be an effective approach to ameliorate hyperthermia and enhance welfare and productivity in dairy systems with incidence of heat stress conditions.

\section{ACKNOWLEDGMENTS}

The Fundação de Amparo à Pesquisa do Estado de São Paulo (São Paulo, Brazil) provided financial support for T. Leiva (grant no. 2015/21224-0).

\section{REFERENCES}

Abbas, A. K., and A. H. Lichtman. 2007. Cellular and Molecular Immunology. 6th ed. Saunders Co., Philadelphia, PA.

AOAC. 1990. Official Method of Analysis. 15th ed. Assoc. Off. Anal. Chem., Arlington, VA.

AOAC International. 1999. Official Method of Analysis. 16th ed. AOAC Int., Arlington, VA.

Beede, D. K., and R. J. Collier. 1986. Potential nutritional strategies for intensively managed cattle during thermal stress. J. Anim. Sci. 62:543-554

Bernhard, B. C., N. C. Burdick, R. J. Rathmann, J. A. Carroll, D. N. Finck, M. A. Jennings, T. R. Young, and B. J. Johnson. 2012. Chromium supplementation alters both glucose and lipid metabolism in feedlot cattle during the receiving period. J. Anim. Sci. 90:4857-4865.

Brandão, A. P., R. F. Cooke, F. N. Corrá, M. B. Piccolo, R. Gennari, T. Leiva, and J. L. M. Vasconcelos. 2016. Physiologic, health, and production responses of dairy cows supplemented with an immunostimulant feed ingredient during the transition period. J. Dairy Sci. 99:5562-5572.

Burdick, N. C., J. A. Carroll, J. D. Chapman, T. H. Welsh, R. C. Vann, and R. D. Randel. 2012. OmniGen-AF supplementation modulates the physiological and acute phase response of Brahman heifers to an endocrine challenge. J. Anim. Sci. 90(Suppl. 3):221.

Burdick Sanchez, N. C., J. O. Buntyn, J. A. Carroll, T. Wistuba, K. DeHann, S. E. Sieren, S. J. Jones, and T. B. Schmidt. 2014 Enhancement of the acute phase response to lipopolysaccharide in feedlot steers supplemented with OmniGen-AF. J. Anim. Sci. 92(E-Suppl. 2):37-38.

Burnett, T. A., A. M. L. Madureira, B. F. Silper, A. Nadalin, A. M. Tahmasbi, D. M. Veira, and R. L. A. Cerri. 2014. Short communication: Factors affecting hair cortisol concentration in lactating dairy cows. J. Dairy Sci. 97:7685-7690.

Butler, W. R. 2003. Energy balance relationships with follicular development ovulation and fertility in postpartum dairy cows. Livest. Prod. Sci. 83:211-218.

Carroll, J. A., and N. E. Forsberg. 2007. Influence of stress and nutrition on cattle immunity. Vet. Clin. Food. Anim. 23:105-149.

Chapman, J. D., S. S. Bascom, L. O. Ely, G. A. Holub, J. P. Jarrett, J. S. Lanier, D. Kirk, D. E. Nuzback, A. D. Rowson, and T. J. Wistuba. 2016. Health, milk yield and milk quality records evaluated in 787 dairy herds before and during OmniGen-AF ${ }^{\circledR}$ supplementation to dry and lactating cows. J. Dairy Sci. 99(E-Suppl. 1):649.

Christison, G. I., and H. D. Johnson. 1972. Cortisol turnover in heatstressed cows. J. Anim. Sci. 35:1005-1010.

Collier, R. J., J. L. Collier, R. P. Rhoads, and L. H. Baumgard. 2008. Invited review: Genes involved in the bovine heat stress response. J. Dairy Sci. 91:445-454.

Cook, C. J., D. J. Mellor, P. J. Harris, J. R. Ingram, and L. R. Matthews. 2000. Hands-on and hands-off measurement of stress. Pages 123-146 in The Biology of Animal Stress. G. P. Moberg and J. A. Mench, ed. CABI Publishing, Wallingford, UK.

Cooke, R. F., and J. D. Arthington. 2013. Concentrations of haptoglobin in bovine plasma determined by ELISA or a colorimetric method based on peroxidase activity. J. Anim. Physiol. Anim. Nutr. (Berl.) 97:531-536.

Cooke, R. F., and D. W. Bohnert. 2011. Bovine acute-phase response following corticotrophin-release hormone challenge. J. Anim. Sci. $89: 252-257$.

Cooke, R. F., J. A. Carroll, J. Dailey, B. I. Cappellozza, and D. W. Bohnert. 2012. Bovine acute-phase response following different 
doses of corticotrophin-release hormone challenge. J. Anim. Sci. 90:2337-2344.

De Rensis, F., and R. J. Scaramuzzi. 2003. Heat stress and seasonal effects on reproduction in the dairy cow-A review. Theriogenology 60:1139-1151.

Fabris, T., J. Laporta, F. N. Correa, Y. M. Torres, D. J. Kirk, D. J. McLean, J. D. Chapman, and G. E. Dahl. 2016. Effect of OmniGen-AF ${ }^{\circledR}$ and heat stress during the dry period on subsequent performance of cows. J. Dairy Sci. 99(E-Suppl. 1):339.

Giesecke, W. H. 1985. The effect of stress on udder health of dairy cows. Onderstepoort J. Vet. Res. 52:175-193.

Hall, L. W., F. A. Rivera, F. Villar, J. D. Chapman, N. M. Long, and R. J. Collier. 2014. Evaluation of OmniGen-AF ${ }^{\circledast}$ in lactating heat-stressed Holstein cows. Pages 16-26 in 25th Annual Florida Ruminant Nutrition Symposium. Accessed Oct. 29, 2016. http:// dairy.ifas.ufl.edu/rns/2014/2014_proceedings.pdf.

Hamzaoui, S., A. A. K. Salama, E. Albanell, X. Such, and G. Caja. 2013. Physiological responses and lactational performances of late lactating dairy goats under heat stress conditions. J. Dairy Sci. 96:6355-6365.

Jorritsma, R., T. Wensing, T. A. M. Kruip, P. L. A. M. Vos, and J. P. T. M. Noordhuizen. 2003. Metabolic changes in early lactation and impaired reproductive performance in dairy cows. Vet. Res. 34:11-26.

Kadzere, C. T., M. R. Murphy, N. Silanikove, and E. Maltz. 2002. Heat stress in lactating dairy cows; A review. Livest. Prod. Sci. 77:59-91.

Leiva, T., R. F. Cooke, A. P. Brandão, A. C. Aboin, J. Ranches, and J. L. M. Vasconcelos. 2015. Effects of excessive energy intake and supplementation with chromium propionate on insulin resistance parameters in lactating dairy cows. Livest. Sci. 180:121-128.

Leiva, T., R. F. Cooke, A. P. Brandão, U. Pardelli, R. O. Rodrigues, F. N. Corrá, and J. L. M. Vasconcelos. 2016. Effects of concentrate type and chromium propionate supplementation on insulin sensitivity parameters, milk production, and reproductive outcomes of lactating dairy cows consuming excessive energy. Animal https:// doi.org/10.1017/S1751731116001713.

Lima, F. S., M. F. Sá Filho, L. F. Greco, and J. E. P. Santos. 2012. Effects of feeding rumen-protected choline on incidence of diseases and reproduction of dairy cows. Vet. J. 193:140-145.

Murata, H., N. Shimada, and M. Yoshioka. 2004. Current research on acute phase proteins in veterinary diagnosis: An overview. Vet. J. 168:28-40.

NRC. 2001. Nutrient Requirements of Dairy Cattle. Natl. Acad. Sci., Washington, DC.

Nyman, A. K., U. Emanuelson, K. Holtenius, K. L. Ingvartsen, T. Larsen, and K. P. Waller. 2008. Metabolites and immune variables associated with somatic cell counts of primiparous dairy cows. J. Dairy Sci. 91:2996-3009.

Rhoads, M. L., R. P. Rhoads, M. J. VanBaale, R. J. Collier, S. R. Sanders, W. J. Weber, B. A. Crooker, and L. H. Baumgard. 2009 Effects of heat stress and plane of nutrition on lactating Holstein cows: I. Production, metabolism, and aspects of circulating somatotropin. J. Dairy Sci. 92:1986-1997.

Ryman, V. E., S. C. Nickerson, F. M. Kautz, D. J. Hurley, L. O. Ely, Y. Q. Wang, and N. E. Forsberg. 2013. Effect of dietary supplementation on the antimicrobial activity of blood leukocytes isolated from Holstein heifers. Res. Vet. Sci. 95:969-974.

St-Pierre, N. R., B. Cobanov, and G. Schnitkey. 2003. Economic losses from heat stress by US livestock industries. J. Dairy Sci. 86:E52E77.

Vazquez-Añon, M., S. Bertics, M. Luck, R. R. Grummer, and J. Pinheiro. 1994. Peripartum liver triglyceride and plasma metabolites in dairy cows. J. Dairy Sci. 77:1521-1528.

Vizcarra, J. A., R. P. Wettemann, J. C. Spitzer, and D. G. Morrison. 1998. Body condition at parturition and postpartum weight gain influence luteal activity and concentrations of glucose, insulin, and nonesterified fatty acids in plasma of primiparous beef cows. J. Anim. Sci. 76:927-936.

Wang, Y. Q., S. B. Puntenney, J. L. Burton, and N. E. Forsberg. 2009. Use of gene profiling to evaluate the effects of a feed additive on immune function in periparturient dairy cattle. J. Anim. Physiol. Anim. Nutr. (Berl.) 93:66-75.

West, J. W. 1994. Interactions of energy and bovine somatotropin with heat stress. J. Dairy Sci. 77:2091-2102.

West, J. W. 2003. Effects of heat-stress on production in dairy cattle. J. Dairy Sci. 86:2131-2144.

Wildman, E. E., G. M. Jones, P. E. Wagner, R. L. Boman, H. F Troutt, and T. N. Lesch. 1982. A dairy cow body condition scoring system and its relationship to selected production characteristics. J. Dairy Sci. 65:495-501.

Willard, S., S. Gandy, S. Bowers, K. Graves, A. Elias, and C. Whisnant. 2003. The effects of GnRH administration post-insemination on serum concentrations of progesterone and pregnancy rates in dairy cattle exposed to mild summer heat stress. Theriogenology $59: 1799-1810$

Wise, M. E., D. V. Armstrong, J. T. Huber, R. Hunter, and F. Wiersma. 1988. Hormonal alterations in the lactating dairy cow in response to thermal stress. J. Dairy Sci. 71:2480-2485.

Zimbleman, R. B., R. P. Rhoads, L. H. Baumgard, and R. J. Collier. 2009. Revised temperature humidity index (THI) for high producing dairy cows. J. Dairy Sci. 92(E-Suppl. 1):347. (Abstr.) 